\title{
Role of Prostate Specific Antigen (PSA) in Pathogenesis of Prostate Cancer
}

\author{
Saleh Altuwaijri ${ }^{1,2,3}$ \\ ${ }^{1}$ SAAD Research \& Development Center (SRDC), Saad Specialist Hospital, Al Khobar, KSA; ${ }^{2}$ King Abdulaziz City for Science \& \\ Technology (KACST), Riyadh, KSA; ${ }^{3}$ University of Qassim, Qassim, KSA. \\ Email: saltuwaijri@saadmedical.com
}

Received April 30 ${ }^{\text {th }}, 2012$; revised May $31^{\text {st }}, 2012$; accepted June $13^{\text {th }}, 2012$

\begin{abstract}
Prostate cancer (PCa) is most common diagnosed cancer in men and it is second most common cause of male cancer death. Many factors have been implicated in the pathogenesis of PCa. Although many papers have discussed the prostate specific antigen (PSA) as biomarker of PCa, very few have addressed its rule in the carcinogenesis, metastasis and invasion of PCa. In this article we will review the pathological role of PSA, as a potential target in the therapeutics of PCa.
\end{abstract}

Keywords: Prostate Cancer; Prostate Specific Antigen; PSA; Androgen Receptor

\section{Introduction}

Prostate cancer is the most common diagnosed cancer in men and it is the second most common cause of male cancer death [1]. The incidence of invasive prostate cancer differ according to ethnic group and country as it is the lowest in China (1.9 per 100,000 per year) and highest in North America and Scandinavia, especially in AfricanAmerican people (137 per 100,000 per year). However, histologic (latent) prostate cancer is much more common than the invasive one. It is revealed from several autopsy studies in about 600 men that histological prostate cancer is common in $30 \%$ of men around age $30,50 \%$ of men around 50 and more than $75 \%$ of men in older than 85 years. In other words, the majority of prostate cancers in the population are latent and clinically not significant [2]. Although PSA is used for many years as surrogate biomarker for screening of prostate cancer, it seems most of, if not all, newest guidelines did not recommend $[3,4]$. Recently, more data implied that PSA is not only an AR (androgen receptor) target gene, but involved also in the carcinogenesis, metastasis and invasion of PCa. Although more investigations into the biological function of PSA are needed, the significance of PSA in the prostate cancer has been highlighted in this review, and may represent, therefore, as an attractive drug targets for therapeutic intervention of PCa. Prostate-specific antigen (PSA) is a 33-kd single-chain glycoprotein containing 237 amino acid residues, 4 carbohydrate side chains, and multiple disulfide bonds [5,6]. It is encoded by KLK3 gene, a member of the 15 genes in kallikrein gene family which colocal- izes to the same chromosomal region (19q13.4) in human [7]. Among the whole kallikrein family members, proteins expressed by KLK2 and KLK3 genes are considered closely related KLKs, that set into one subgroup and possess $80 \%$ similarity at the amino acid sequence level [7]. Both KLK3 and KLK2 genes are regulated by androgen receptor and progestin [8-10]. PSA is localized predominantly in the cytoplasm of glandular epithelia, from where it is likely to be secreted from both normal and neoplastic prostate cells [11] and although the prostate stroma is androgen-responsive, it does not express KLK3 [12]. It is synthesized as preproenzymes, proteolytically processed by removal of the signal peptide prior to its secretion as an inactive proenzymes. Pro-PSA is the latent form of the PSA enzyme and has to be activated extracellularly [13]. Processing to obtain the enzymatically active form occurs by further proteolytic removal of a 4 - 9 amino acid long peptide at the N-terminus (with the exception of KLK15) [14]. Being detected in other cancers, including breast, lung, and uterine cancer, and in normal breast and pituitary gland, the expression of PSA as well as KLK2 is shown to be not restricted to the prostate. PSA is known to be present in biological fluids, such as serum, seminal plasma, milk of lactating women, salivary glands, pancreas, thyroid gland, placenta and amniotic fluid [15].

\section{Role of PSA in the Pathophysiology of Prostate Cancer}

Besides its well-known physiological function of lique- 
fying seminal clot [16], PSA is also involved in tumor growth, invasion and metastasis of prostate cancer. We are trying our best to summarize all the significant findings focusing specifically on these studies.

\subsection{Genetics}

\subsubsection{PSA Genotype GG}

The large-scale cohort studies about on genetic susceptibility to prostate cancer, confirmed by two different groups in the United States, suggested that people with PSA genotype GG (high affinity to AR in promoter) have more than 5 - 7 fold increase in prostate cancer risk, and also conferred that it posses higher risk than polymorphism in one of the gene alone $[17,18]$. Both studies suggested the gene-gene interaction in the etiology of prostate cancer between PSA and AR.

\subsubsection{Polymorphism of G-158A and G-4643A}

G-158A polymorphism (rs266882) involving the promoter of PSA gene is associated with high serum PSA level, tumor volume, stage and grade of disease, lymph node invasion and circulating tumor cells in some studies. Also, G-4643A polymorphism (rs925013) involving the promoter of PSA gene is associated, surprisingly, with high risk of prostate cancer [12]. In a recent study, Penney et al. reported that 4 alleles (rs266878, rs174776, rs 1058205 and rs2569735) are associated with low PSA level and significantly associated with lower risk of prostate cancer [19].

\subsection{Oxidative Stress}

In William's review, it was found that PSA stimulates reactive oxygen species generation in $\mathrm{LNCaP}, \mathrm{PC} 3$ and DU145 cells and redox was implicated in many cancers including prostate cancer [20]. The use of antioxidant for preventing and treating PCa supported this evidence [21].

\subsection{Invasion \& Metastasis}

\subsubsection{PCa Invasion}

It is found that PSA degrades some extracellular matrix proteins and promotes urokinase-type plasminogen activator and both are known to be important factors for $\mathrm{PCa}$ in tumor invasion and metastasis [22].

\subsubsection{Insulin-like Frowth Factor}

PSA cleaves insulin-like growth factor binding protein 3 (IGFBF-3) to liberate IGF-1 [23], catalyzing the hydrolysis of several ECM which facilitate cell invasion [24], acting as a mitogen for androgen responsive human prostate cancer LNCaP [25], stimulating BPH-derived stromal cells proliferation [26], processing osteoblastic bone metastasis by cleavage of PTHrP [27] and facilitating progression of prostate cancer cells by downregulating of $\mathrm{E}$ - cadherin and upregulating vimentin expression which consequently induces epithelial-mesenchymal transition [28].

PSA was found to activate specifically the small latent form of TGFb2 suggesting that PSA can directly stimulate a variety of cellular processes through the release of active TGFb2 stored within the matrix of the prostatic stroma [29].

\section{4. p53 and Bcl-2}

In a study carried out on the human prostate cancer samples, p53 mutation was positively correlated with serum PSA and tumor extent, and overexpression of Bcl-2 (Bcell lymphoma 2) which has antiapoptotic properties was associated with high serum PSA only [30]. These studies implied that PSA is not only an AR target gene, but also participates in the etiology of prostate cancer, and may somehow interact with AR.

We found prostate-specific antigen might promote prostate cancer proliferation via functioning as a coactivator to enhance ARA70-induced androgen receptor transactivation without involving its protease activity. The prostate-specific antigen-induced androgen receptor transactivation might then result in the suppression of p53 expression via modulation of Mdm2/HoxA5/Egr-1 pathways. The consequence of p53 suppression might result in decreased apoptosis. Cell growth will be arrested at the G1 phase and this would occur via modulation of the bax/ bcl-2/caspase 3 and p21/cdks signal pathways. Taken together, this newly identified signal pathway of prostatespecific antigen ARA70/androgen receptor, p53 apoptosis/ G1 arrest might allow prostate-specific antigen to become a new therapeutic target to battle the prostate cancer. Also, prostate-specific antigen-siRNA or smaller molecules that can degrade prostate-specific antigen or interrupt the interaction between prostate-specific antigen and ARA70 might be developed as alternative approaches to suppress the prostate cancer growth [31].

\subsection{Crosstalk between PSA and AR}

The primary regulator of PSA expression in the human prostate is AR and its gene is located on chromosome Xq-11-12 [32]. AR results in the induction of PSA expression through three androgen response elements (AREs) located in the proximal $6 \mathrm{~kb}$ of the PSA promoter [33]. Although AR still exists in hormone refractory prostate cancers, the abnormal PSA elevation may not attribute to AR regulation in this stage. It has been reported, in addition to androgens, PSA expression may be induced by glucocorticoids [34], progestin [35], GAGATA binding protein [36], and ETS transcription factors [37]. However, the significance of AR-independent PSA expression remains unclear.

PSA is expressed by androgen-sensitive LNCaP (hu- 
man prostate adenocarcinoma cell line) cells, while Du145 and PC3, which are often used as models of androgen independent prostate cancer, lack AR expression and do not produce PSA. But AR transfected PC3 cells produces and secretes PSA in an androgen-dependent manner [38]. This result highlights the importance of AR activity for PSA expression in this cell line.

LNCaP cotransfection experiments with AR and SRY expression vectors and a luciferase reporter gene showed that the strong stimulation of PSA by AR in the presence of dihydrotestosterone was markedly repressed when cells were cotransfected with SRY [39].

Many recent studies revealed the pivotal rule of the PSA in the prostate cancer. Saxena et al. investigated the localization of PSA, AR and Src in intracellular compartment of LNCaP or C4-2B PrCa cells that were under stimulation of synthetic androgen. They found that most of fractions of PSA accumulated in the nuclei of these androgen-stimulated PrCa cells, compared to the control, and the cytoplasmic fractions aggregated in certain area of the cytoplasm and specifically with cis-medial Golgi apparatus, thereby suggesting that signal peptides were still added. They investigated also the effect of low PSA expression (by shRNA) on AR. They found that shRNA silencing of PSA is associated with extremely low AR levels in C4-2B and VCaP cells suggesting, that PSA is, at least, one of mediators regulating $\mathrm{AR}$ expression in $\mathrm{PrCa}$ cells [14].

\subsection{The Effect of Low PSA}

Williams et al. studied the effect of low PSA (achieved by shRNA lentivirus) on the growth and tumerigenicity in vitro and in vivo. They found that low PSA expression in $\mathrm{LNCaP}$ is associated with low growth rate in vitro and the doubling time increased from 2 days to 11 days. In vivo, they found that low PSA expression and serum level is associated with lower tumor weight. In addition, they found that low PSA expression is associated with change in expression of many proteins which may indicate that PSA is part of regulatory mechanism of their expressions [40].

\subsection{The Baseline of PSA}

Many studies reveal that androgen level in African American men, especially above age of 40 years, is not higher than white Caucasian [41-43]. In addition, an increase in prostate cancer incidence coincides with a gradual decrease in testosterone levels with advancing age [44]. Also, the decrease in bioavailability of testosterone (i.e., a combination of free testosterone and the fraction weakly bound to albumin) with aging is reported to be considerably greater than the total testosterone decline [45]. The increase of PSA with age is partially influenced by benign prostatic hyperplasia [46]. Interestingly, it has been found that African American men have higher baseline of PSA value and higher incidence of prostate cancer and mortality as well [3]. Also, new study found that native Chinese young men have a baseline level of PSA lower than African American and Caucasian American young men; keeping in our mind that Chinese men have lowest incidence of $\mathrm{PCa}$ [47]. Hence, this correlation between PSA baseline and the incidence of PCa may elaborate the role of PSA in this cancer.

\subsection{PSA Lowering Substances}

If any substance is found to decrease the PSA regardless of the pathway (which is associated with low incidence of $\mathrm{PCa}$ ), this may add to the role PSA in the pathophysiology of PCa. Many studies reveal that Curcumin, [48] (-)-epigallocatechin-3-gallate, a major constituent of green tea [49], decursin [50], capsaicin [51] and the potent PSA inhibitor boron [52] fall in this category.

\section{Discussion}

In this article, we have summarized the role of PSA primarily as an independent factor to promote initiation, invasion and metastasis of PCa. Although some authors are supporting this hypothesis [20,53] However, however, some authors are not [54]. The association between low density protein (LDL) and lowering drugs, which were found to lower the PSA, and increase the risk of $\mathrm{PCa}$ is revealed in 2 studies but the larger part show the opposite or no significant difference as thoroughly reviewed by Gazzerro et al. [55]. Also, mentioning that the $5 \alpha$-reductase inhibitors, which lower PSA through AR signaling, as they increase the aggressive pattern of PCa $[56,57]$ only seems to be biased. It remains unclear if the high-grade $\mathrm{PCa}$ in patients consuming these drugs is the side-effect of these drugs or an artifact as reviewed in detail [58] and these adverse effects of such drugs still need to be evaluated [59]. The other probable reason would be the $5 \alpha$-reductase inhibitors, which support the role of PSA in PCa by decreasing the overall incidence of PCa. In addition, some authors attribute the low incidence of $\mathrm{PCa}$ in Chinese population to the green tea which lowers the PSA without increasing the high-grade of PCa [49]. Some studies revealed that PSA inhibits the growth and migration of endothelial cells by inhibiting endothelial cell response to the fibroblast growth factor 2 (FGF-2) and vascular endothelial growth factor (VEGF). They have the ability cleave plasminogen, causing the release of biologically active angiostatin-like fragments and can essentially slow the progression of the disease through this antiangiogenic activity $[32,60]$; in addition to that, it has been revealed that PSA-inhibitors suppress the antiangiogenic effect of PSA in an angiogenesis model [61]. 
Also, a recent study established that low PSA expressing $\mathrm{PCa}$ cells maintain tumor-regenerating capacity and resistance to androgen-deprivation. Although the overall evidences are supporting PSA as the promoter in the "vague game" of the PCa, the dual effect of PSA in the pathogenesis cannot be excluded. It is still possible that the story of PSA is equivalent to story of androgen as the latter promote proliferation from one side and induce apoptosis of PCa cells in another side as our study revealed [62] The clinical significance targets the PSA as a potential therapeutic agent specially for castration-resistant PCa. Therefore, we are awaiting further studies to expose the challenging mystery of PSA.

\section{REFERENCES}

[1] A. Jemal, R. Siegel, E. Ward, Y. Hao, J. Xu and M. J. Thun, "Cancer Statistics," CA: A Cancer Journal for Clinicians, Vol. 59, No. 4, 2009, pp. 225-249. doi:10.3322/caac. 20006

[2] H. Grönberg, "Prostate Cancer Epidemiology," Lancet, Vol. 361, No. 9360, 2003, pp. 859-864. doi:10.1016/S0140-6736(03)12713-4

[3] M. E. O'Rourke, "The Prostate-Specific Antigen Screening Conundrum Examining the Evidence," Seminars in Oncology Nursing, Vol. 27, No. 4, 2011, pp. 251-259. doi:10.1016/j.soncn.2011.07.003

[4] V. A. Moyer, "Screening for Prostate Cancer: US Preventive Services Task Force Recommendation Statement," Annals of Internal Medicine, 21 May 2012.

[5] J. Lovgren, T. Piironen and C. Overmo, "Production of Recombinant PSA and HK2 and Analysis of Their Immunologic Cross-Reactivity," Biochemical and Biophysical Research Communications, Vol. 213, No. 3, 1995, pp. 888-895. doi:10.1006/bbrc.1995.2212

[6] M. C. Wang, L. D. Papsidero, M. Kuriyama, L. A. Valenzuela, et al., "Prostate Antigen: A New Potential Marker for Prostatic Cancer," The Prostate, Vol. 2, No. 1, 1981, pp. 89-96. doi:10.1002/pros.2990020109

[7] C. A. Borgono, I. P. Michael and E. P. Diamandis, "Human Tissue Kallikreins: Physiologic Roles and Applications in Cancer," Molecular Cancer Research, Vol. 2, No. 5, 2004, pp. 257-280.

[8] P. H. Riegman, R. J. Vlietstra, J. A. van der Korput, A. O. Brinkmann and J. Trapman, "The Promoter of the Prostate-Specific Antigen Gene Contains a Functional Androgen Responsive Element," Molecular Endocrinology, Vol. 5, No. 12, 1991, pp. 1921-1930. doi:10.1210/mend-5-12-1921

[9] N. Zarghami, L. Grass, E. R. Sauter and E. P. Diamandis, "Prostate-Specific Antigen in Serum during the Menstrual Cycle," Clinical Chemistry, Vol. 43, No. 10, 1997, pp. 1862-1867.

[10] P. Murtha, D. J. Tindall and C. Y. Young, "Androgen Induction of a Human Prostate-Specific Kallikrein, hKLK2: Characterization of an Androgen Response Element in the 5' Promoter Region of the Gene," Biochemistry, Vol. 32,
No. 25, 1993, pp. 6459-6464. doi: $10.1021 / \mathrm{bi00076a020}$

[11] M. E. O'Rourke, "The Prostate-Specific Antigen Screening Conundrum Examining the Evidence," Seminars in Oncology Nursing, Vol. 27, No. 4, 2011, pp. 251-259. doi:10.1016/j.sonen.2011.07.003

[12] M. G. Lawrence, J. Lai and J. A. Clements, "Kallikreins on Steroids Structure, Function, \& Hormonal Regulation of Prostate-Specific Antigen \& the Extended Kallikrein Locus," Endocrine Reviews, Vol. 31, No. 4, 2010, pp. 407-446. doi:10.1210/er.2009-0034

[13] A. P. Cumming, S. N. Hopmans, S. Vukmirović-Popović and W. C. Duivenvoorden, "PSA Affects Prostate Cancer Cell Invasion in Vitro \& Induces an Osteoblastic Phenotype in Bone in Vivo," Prostate Cancer and Prostatic Diseases, Vol. 14, No. 4, 2011, pp. 286-294. doi:10.1038/pcan.2011.34

[14] P. Saxena, M. Trerotola, T. Wang, J. Li, A. Sayeed, et al., "PSA Regulates Androgen Receptor Expression in Prostate Cancer Cells," Prostate, 28 September 2011. doi:10.1002/pros.21482

[15] A. Y. Olsson, A. Bjartell, H. Lilja and A. Lundwall, "Expression of Prostate-Specific Antigen (PSA) and Human Glandular Kallikrein 2 (hK2) in Ileum and Other Extraprostatic Tissues," International Journal of Cancer, Vol. 113, No. 2, 2005, pp. 290-297. doi:10.1002/ijc.20605

[16] H. Lilja, J. Oldbing, G. Rannevik and C. B. Laurell, "Seminal Vesicle-Secreted Proteins and Their Reactions during Gelation and Liquefaction of Human of Human Semen," Journal of Clinical Investigation, Vol. 80, No. 2, 1987, pp. 281-185. doi:10.1172/JCI113070

[17] W. Sieh, K. L. Edwards, A. L. Fitzpatrick, S. L. Srinouanprachanh, F. M. Farin, et al., "Genetic Susceptibility to Prostate Cancer: Prostate-Specific Antigen and Its Interaction with the Androgen Receptor," Cancer Causes Control, Vol. 17, No. 2, 2006, pp. 187-197. doi:10.1007/s10552-005-0454-8

[18] W. Xue, R. A. Irvine, M. C. Yu, R. K. Ross, G. A. Coetzee and S. A. Ingles, "Susceptibility to Prostate Cancer: Interaction between Genotypes at the Androgen Receptor and Prostate-Specific Antigen Loci," Cancer Research, Vol. 60, 2000, pp. 839-841.

[19] K. L. Penney, F. R. Schumacher, P. Kraft, L. A. Mucci, H. D. Sesso, J. Ma, Y. Niu, J. K. Cheong, D. J. Hunter, M. J. Stampfer and S. I. Hsu, "Association of KLK3 (PSA) Genetic Variants with Prostate Cancer Risk and PSA Levels," Carcinogenesis, Vol. 32, No. 6, 2011, pp. 853859. doi:10.1093/carcin/bgr050

[20] S. A. Williams, P. Singh, J. T. Isaacs and S. R. Denmeade, "Does PSA Play a Role as a Promoting Agent during the Initiation and/or Progression of Prostate Cancer," The Prostate, Vol. 67, No. 3, 2007, pp. 312-329.

[21] D. Thapa and R. Ghosh, "Antioxidants for Prostatecancer Chemoprevention: Challenges and Opportunities," Biochemical Pharmacology, Vol. 83, No. 10, 2012, pp. 13191330. doi:10.1016/j.bcp.2011.12.027

[22] M. M. Webber, A. Waghray and D. Bello, "ProstateSpecific Antigen, a Serine Protease, Facilitates Human Prostate Cancer Cell Invasion," Clinical Cancer Research, 
Vol. 1, 1995, pp. 1089-1094.

[23] P. Cohen, H. C. Graves, D. M. Peehl, M. Kamarei, et al., "Prostate-Specific Antigen (PSA) Is an Insulin-like Growth Factor Binding Protein-3 Protease found in Seminal Plasma," The Journal of Clinical Endocrinology \& Metabolism, Vol. 75, No. 4, 1992, pp. 1046-1053. doi:10.1210/jc.75.4.1046

[24] R. Pandey, N. Patil and M. Rao. "Proteases and Protease Inhibitors: Implications in Antitumorigenesis and Drug Development," International Journal of Human Genetics, Vol. 7. No. 1, 2007, pp. 67-82.

[25] L. G. Wang, X. M. Liu, W. Kreis and D. R. Budman, "Down Regulation of Prostate-Specific Antigen Expression by Finasteride through Inhibition of Complex Formation between Androgen Receptor and Steroid Receptor Binding Consensus in the Promoter of the PSA Gene in LNCaP Cells," Cancer Research, Vol. 57, No. 4, 1997, pp. 714-719.

[26] D. M. Sutkowski, R. L. Goode, J. Banial, C. Teater, et al., "Growth Regulation of Prostatic Stromal Cells by Prostate-Specific Antigen," Journal of the National Cancer Institute, Vol. 91, No. 19, 1999, pp. 1663-1669. doi:10.1093/jnci/91.19.1663

[27] S. D. Cramer, Z. Chen and D. M. Peehl, "Prostate-Specific Antigen Cleaves Parathyroid Hormone-Related Protein in the PTH-like Domain: Inactivation of PTHrPStimulated cAMP Accumulation in Mouse Osteoblasts," Journal of Urology, Vol. 156, No. 2, 1996, pp. 526-531. doi:10.1016/S0022-5347(01)65919-6

[28] T. L. Veveris-Lowe, M. G. Lawrence, R. L. Collard, L. Bui, A. C. Heringtaon, et al., "Kallikrein 4 (hK4) and Prostate-Specific Antigen (PSA) Are Associated with the Loss of E-Cadherin and an Epithelial-Mesenchymal Transition (EMT)-like Effect in Prostate Cancer Cells," EndocrineRelated Cancer, Vol. 12, 2005, pp. 631-643. doi:10.1677/erc. 1.00958

[29] A. M. LeBeau, M. Kostova, C. S. Craik and S. R. Denmeade, "Prostate-Specific Antigen an Overlooked Candidate for the Targeted Treatment and Selective Imaging of Prostate Cancer," The Journal of Biological Chemistry, Vol. 391, No. 4, 2010, pp. 333-343.

doi:10.1515/bc.2010.044

[30] J. T. Lin, J. S. Wang, B. P. Jiann, C. C. Yu, et al., "Correlation of p53 Protein Accumulation and Bcl-2 Overexpression with Histopathological Features in Prostatic Cancer," Journal of the Formosan Medical Association, Vol. 104, No. 11, 2005, pp. 864-867.

[31] Y. Niu, S. Yeh, H. Miyamoto, G. Li, S. Altuwaijri, J. Yuan, R. Han, T. Ma, H. C. Kuo and C. Chang, "Tissue Prostate-Specific Antigen Facilitates Refractory Prostate Tumor Progression via Enhancing ARA70-Regulated Androgen Receptor Transactivation," Cancer Research, Vol. 68, No. 17, 2008, pp. 7110-7119. doi:10.1158/0008-5472.CAN-07-6507

[32] A. H. Fortier, J. W. Holaday, H. Liang, C. Dey, et al., "Recombinant Prostate-Specific Antigen Inhibits Angiogenesis in Vitro and in Vivo," The Prostate, Vol. 56, No. 3, 2003, pp. 212-219. doi:10.1002/pros.10256

[33] H. Yu, E. P. Diamandis, N. Zarghami and L. Grass, "In- duction of Prostate Specific Antigen Production by Steroids and Tamoxifen in Breast Cancer Cell Lines," Breast Cancer Research and Treatment, Vol. 32, No. 3, 1994, pp. 291-300. doi:10.1007/BF00666006

[34] C. B. J. M. Cluetjens, K. Steketee, C. C. E. M. van Eekelen, J. A. G. M. van der Korput, et al., "Both Androgen Receptor and Glucocorticoid Receptor Are Able to Induce Prostate-Specific Antigen Expression, but Differ in Their Growth Stimulating Properties of LNCaP Cells," Endocrinology, Vol. 138, No. 12, 1997, pp. 5293-5300. doi:10.1210/en.138.12.5293

[35] H. Yu, E. P. Diamandis, N. Zarghami and L. Grass, "Induction of Prostate-Specific Antigen Production by Steroids and Tamoxifen in Breast Cancer Cell Lines," Breast Cancer Research and Treatment, Vol. 32, No. 3, 1994, pp. 291-300. doi:10.1007/BF00666006

[36] C. Wang, F. Yeung, P. C. Liu, A. M. Attar, J. Geng, L. W. K. Chung, et al., "Identification of a Novel Transcription Factor, GAGATA-Binding Protein, Involved in Androgen-Mediated Expression of Prostate-Specific Antigen," The Journal of Biological Chemistry, Vol. 278, No. 34, 2003, pp. 32423-32430. doi:10.1074/jbc.M207862200

[37] J. A. R. de Winter, P. J. A. Janssen, H. M. E. B. Sleddens, M. C. T. Verleun-Mooijman, et al., "Androgen Receptor Status in Localized and Locally Progressive Hormone Refractory Human Prostate Cancer," American Journal of Pathology, Vol. 144, 1994, pp. 735-746.

[38] C. D. Chen, D. S. Welsbie, C. Tran, S. H. Baek, et al., "Molecular Determinants of Resistance to Antiandrogen Therapy," Nature Medicine, Vol. 10, 2004, pp. 33-39. doi:10.1038/nm972

[39] S. Koochekpour, "Androgen Receptor Signaling and Mutations in Prostate Cancer," Asian Journal of Andrology, Vol. 12, No. 5, 2010, pp. 639-657. doi:10.1038/aja.2010.89

[40] S. A. Williams, C. A. Jelinek, I. Litvinov, R. J. Cotter, J. T. Isaacs and S. R. Denmeade, "Enzymatically Active Prostate-Specific Antigen Promotes Growth of Human Prostate Cancers," The Prostate, Vol. 71, No. 15, 2011, pp. 1595-1607. doi:10.1002/pros.21375

[41] E. S. Orwoll, C. M. Nielson, F. Labrie, E. Barrett-Connor, J. A. Cauley, et al., "Osteoporotic Fractures in Men (MrOS) Research Group. Evidence for Geographical and Racial Variation in Serum Sex Steroid Levels in Older Men," The Journal of Clinical Endocrinology \& Metabolism, Vol. 95, No. 10, 2010, pp. 151-160. doi: $10.1210 /$ jc. 2009-2435

[42] H. J. Litman, S. Bhasin, C. L. Link, A. B. Araujo and J. B. McKinlay, "Serum Androgen Levels in Black, Hispanic, and White Men," The Journal of Clinical Endocrinology \& Metabolism, Vol. 91, No. 11, 2006, pp. 4326-4334. doi:10.1210/jc.2006-0037

[43] W. S. Kubricht 3rd, B. J. Williams, T. Whatley, P. Pinckard and J. A. Eastham, "Serum Testosterone Levels in African-American and White Men Undergoing Prostate Biopsy," Urology, Vol. 54, No. 6, 1999, pp. 1035-1038. doi:10.1016/S0090-4295(99)00290-3

[44] S. M. Harman, E. J. Metter, J. D. Tobin, J. Pearson and M. 
R. Blackman, "Longitudinal Effects of Aging on Serum Total and Free Testosterone Levels in Healthy Men. Baltimore Longitudinal Study of Aging," The Journal of Clinical Endocrinology \& Metabolism, Vol. 86, No. 2, 2001, pp. 724-731. doi:10.1210/jc.86.2.724

[45] J. P. Deslypere and A. Vermeulen, "Leydig Cell Function in Normal Men: Effect of Age, Life-Style, Residence, Diet, and Activity," The Journal of Clinical Endocrinology \& Metabolism, Vol. 59, No. 5, 1984, pp. 955-962. doi:10.1210/jcem-59-5-955

[46] S. P. Balk, Y. J. Ko and G. J. Bubley, "Biology of Prostate-Specific Antigen," Journal of Clinical Oncology, Vol. 21, No. 2, pp. 383-391. doi:10.1200/JCO.2003.02.083

[47] P. Tang, W. Du, K. Xie, J. Fu, H. Chen, W. Yang and J. W. Moul, "Characteristics of Baseline PSA and PSA Velocity in Young Men without Prostate Cancer: Racial Differences," The Prostate, Vol. 72, No. 2, pp. 173-180. doi:10.1002/pros.21418

[48] L. C. Chung, K. H. Tsui, T. H. Feng, S. L. Lee, P. L. Chang and H. H. Juang, "Curcumin Provides Potential Protection against the Activation of Hypoxia and Prolyl 4-Hydroxylase Inhibitors on Prostate-Specific Antigen Expression in Human Prostate Carcinoma Cells," Molecular Nutrition \& Food Research, Vol. 55, No. 11, 2011, pp. 1666-1676. doi:10.1002/mnfr.201100328

[49] C. P. Chuu, R. Y. Chen, J. M. Kokontis, R. A. Hiipakka and S. Liao, "Suppression Androgen Receptor Signaling Prostate Specific Antigen Expression by Epigallocatechin-3-Gallate Different Progression Stages LNCaP Prostate Cancer," Cancer Letters, Vol. 275, No. 1, 2009, pp. 86-92. doi:10.1016/j.canlet.2008.10.001

[50] Y. Zhang, A. A. Shaik, C. Xing, Y. Chai, L. Li, J. Zhang, W. Zhang, S. H. Kim, J. Lü and C. Jiang, "A Synthetic Decursin Analog with Increased in Vivo Stability Suppresses Androgen Receptor Signaling in Vitro and in Vivo," Investigational New Drugs, 2011. doi:10.1007/s10637-011-9738-x

[51] S. Lehmann, J. O’Kelly, T. Kumagai, J. C. Desmond, M. Pervan, W. H. McBride, M. Kizaki and H. P. Koeffler, "Capsaicin, a Component of Red Peppers, Inhibits the Growth of Androgen-Independent, p53 Mutant Prostate Cancer Cells," Cancer Research, Vol. 66, No. 6, 2006, pp. 3222-3229. doi:10.1158/0008-5472.CAN-05-0087

[52] Reem Smoum, Abraham Rubinstein, Valery M. Dembitsky and Morris Srebnik, "Boron Containing Compounds as Protease Inhibitors," 2012.

[53] A. M. LeBeau, M. Kostova, C. S. Craik and S. R. Denmeade, "Prostate-Specific Antigen: An Overlooked Can- didate for the Targeted Treatment and Selective Imaging of Prostate Cancer," Biological Chemistry, Vol. 391, No. 4, 2010, pp. 333-343. doi:10.1515/bc.2010.044

[54] M. R. Goldstein and L. Mascitelli, "Regarding Prostate-Specific Antigen: Let's Not Shoot the Messenger," QJM, Vol. 105, No. 2, 2012, pp. 207-210. doi:10.1093/qjmed/hcr202

[55] P. Gazzerro, et al. "Pharmacological Actions of Statins: A Critical Appraisal in the Management of Cancer," Pharmacological Reviews, Vol. 64, No. 1, 2012, pp. 102-146. doi:10.1124/pr.111.004994

[56] I. M. Thompson, P. J. Goodman, C. M. Tangen, M. S. Lucia, G. J. Miller, L. G. Ford, M. M. Lieber, R. D. Cespedes, J. N. Atkins, S. M. Lippman, S. M. Carlin, A. Ryan, C. M. Szczepanek, J. J. Crowley and C. A. Coltman Jr., "The Influence of Finasteride on the Development of Prostate Cancer," The New England Journal of Medicine, Vol. 349, No. 3, 2003, pp. 215-224. doi:10.1056/NEJMoa030660

[57] G. L. Andriole, D. G. Bostwick, O. W. Brawley, L. G. Gomella, M. Marberger, F. Montorsi, et al., "Effect of Dutasteride on the Risk of Prostate Cancer," The New England Journal of Medicine, Vol. 362, 2010, pp. 11921202. doi:10.1056/NEJMoa0908127

[58] F. Azzouni and J. Mohler, "Role of 5 $\alpha$-Reductase Inhibitors in Prostate Cancer Prevention and Treatment," Urology, 23 March 2012. doi:10.1016/j.urology.2012.01.024

[59] M. R. Theoret, Y. M. Ning, J. J. Zhang, R. Justice, P. Keegan and R. Pazdur, "The Risks and Benefits of $5 \alpha$-Reductase Inhibitors for Prostate-Cancer Prevention," The New England Journal of Medicine, Vol. 365, No. 2, 2011, pp. 97 99. doi:10.1056/NEJMp1106783

[60] A. H. Fortier, B. J. Nelson, D. K. Grella and J. W. Holaday, "Antiangiogenic Activity of Prostate-Specific Antigen," Journal of the National Cancer Institute, Vol. 91, 1999, pp. 1635-1640. doi:10.1093/jnci/91.19.1635

[61] T. Liu, L. Y. Wu, M. Kazak and C. E. Berkman, "Novel Small Molecule Inhibitors for Prostate-Specific Antigen," The Prostate, Vol. 68, No. 9, 2008, pp. 955-964. doi:10.1002/pros.20753

[62] S. Altuwaijri, H. K. Lin, K. H. Chuang, W. J. Lin, S. Yeh, L. A. Hanchett, M. M. Rahman, H. Y. Kang, M. Y. Tsai, Y. Zhang, L. Yang and C. Chang, "Interruption of Nuclear Factor Kappab Signaling by the Androgen Receptor Facilitates 12-O-Tetradecanoylphorbolacetate-Induced Apoptosis in Androgen-Sensitive Prostate Cancer LNCaP Cells," Cancer Research, Vol. 63, No. 21, 2003, pp. 71067112 . 